\title{
Rehabilitation in the treatment of mandibular condyle fractures
}

\author{
Anna Rzewuska ${ }^{1, B, D-F}$, Edward Kijak ${ }^{2, B, C}$, Ludmiła Halczy-Kowalik' ${ }^{1, A, C-F}$ \\ ${ }^{1}$ Department of Maxillofacial Surgery, Pomeranian Medical University of Szczecin, Poland \\ 2 Department and Division of Prosthodontics, Pomeranian Medical University of Szczecin, Poland \\ A - research concept and design; $\mathrm{B}$ - collection and/or assembly of data; $\mathrm{C}$ - data analysis and interpretation; \\ $D$ - writing the article; $E$ - critical revision of the article; $F$ - final approval of the article
}

Address for correspondence

Anna Rzewuska

E-mail: anna.rzewuska@wp.pl

Funding sources

None declared

Conflict of interest

None declared

Received on June 7, 2020

Reviewed on June 28, 2020

Accepted on 0ctober 2, 2020

Published online on March 31, 2021

Cite as

Rzewuska A, Kijak E, Halczy-Kowalik L. Rehabilitation in the treatment of mandibular condyle fractures. Dent Med Probl. 2021;58(1):89-96. doi:10.17219/dmp/128092

DOI

$10.17219 / \mathrm{dmp} / 128092$

Copyright

○) 2021 by Wroclaw Medical University

This is an article distributed under the terms of the

Creative Commons Attribution 3.0 Unported License (CC BY 3.0)

(https://creativecommons.org/licenses/by/3.0/).

\section{Abstract}

Background. The objective of rehabilitation after the treatment of a mandibular condyle fracture is to retrieve the effortless, symmetrical opening of the jaws with the preservation of appropriate movements to the sides, and appropriate occlusion without a sense of tension in the mastication muscles or pain sensations.

Objectives. The aim of the article was to establish the conditions of the rehabilitation of temporomandibular joint (TMJ) after the surgical treatment of a fractured condyle.

Material and methods. The research featured 46 of patients treated surgically between January 2, 2017 and December 30, 2017. The open reduction and rigid internal fixation (ORIF) was the method mainly applied. Rehabilitation with the use of the Delphi technique was implemented in each patient. The assessment of the mastication organ was mostly performed at 3 and 6 weeks since the beginning of rehabilitation. In every patient, the interincisal distance was measured; in chosen cases, the range and trajectory of the condyle movements, and the trajectory of the secant point during jaw opening were defined with the use of the Zebris ${ }^{\circledR}$ JMA device.

Results. In 45 patients, a full reposition and immobilization of 52 bone fragments of fractured mandibular condyles was obtained. The displacement of the midline of the mandible in occlusion or an incorrect occlusion contact determined the decision on the application of intermaxillary fixation in 8 patients for a period of 2 weeks. The minimal jaw opening of $40 \mathrm{~mm}$ was achieved in 41 patients after 6 weeks of rehabilitation. In 5 of the rest of the patients, rehabilitation had to be continued. The reassessment of the $X$-ray images and additional computed tomography (CT) diagnosis in three-dimensional (3D) reconstruction in those patients revealed the possible causes of difficulties in the restoration of the stomatognathic system functions - the injuries of the muscles or ligaments connected with the joint.

Conclusions. The extension of radiological diagnostics with a CT examination may improve the assessment of the restored TMJ function after the surgical treatment of a fractured mandibular condyle.

Key words: condylar fractures, self-control rehabilitation, temporomandibular joint injuries 


\section{Introduction}

The frequency of fractures within the area of the mandibular condyle is assessed to be over $30 \%$ of all mandible fractures, and their incidence is in the range of $20-62 \%{ }^{1-3}$ Mastering the surgical technique and enriching the range of tools with new solutions, including the endoscopic treatment of fractures, have resulted in a more frequent use of open plate osteosynthesis in the fracture treatment as compared to the $20^{\text {th }}$ century. The choice of a treatment method depends on the type of fracture, the displacement of the condyle head after the injury, the possibility of the reconstruction of the tooth contact in the opposite arches in habitual occlusion, and the decision of a patient who had been presented with the benefits and possible implications of closed reduction and maxillomandibular fixation (CRMMF) or open reduction and rigid internal fixation (ORIF). ${ }^{4-7}$ The minimalization of damage resulting from ORIF, such as the facial nerve injury, visible scarring or salivary fistula formation, is possible with the use of the intraoral approach or endoscopic-assisted ORIF., ${ }^{8,9}$ A full restoration of the stomatognathic system functions requires the implementation of rehabilitation after CRMMF as well as after ORIF. ${ }^{10}$ Recommended rehabilitation techniques include, in addition to the auto-massage of the muscles involved in chewing, the introduction, at 2-3 days after surgery, of active jaw opening, the extension and mediotrusion of the jaw, performed by patients in front of the mirror to control the range and proper trajectory of movements. In the absence of functional progress at the $7^{\text {th }}$ day after surgery, the authors recommend a passive, mild therapy involving stretching with fingers, spatulas or wooden wedges. The effect of rehabilitation depends to a large extent on patient self-discipline. .,11,12 $^{\text {. }}$

The beneficial impact of the functional rehabilitation of the oral cavity and speech rehabilitation on the reconstruction of bone tissue after a mandibular condyle fracture is commonly emphasised., ${ }^{5,12}$ Due to a mechanical load within the area of bone fracture, a lesser loss of bone substance in the bone fragment circuit is observed as well as an increase in the bone number between the bone fragments within the physiological limits. In these conditions, the osteoclast resorption at the external sites of anatomical growth modeling is inhibited and new, immature scaffolding is created, including de novo a rich supply of capillaries. ${ }^{13}$

A lack of standardized programs of rehabilitation of the oral cavity functions after a mandibular condyle fracture results in difficulties in the assessment of treatment outcomes. In 2016, van der Merve and Barnes presented the Delphi technique, which is a complex method of temporomandibular joint (TMJ) rehabilitation after a mandibular condyle fracture. ${ }^{14}$ The Delphi technique emerged as an effect of the compatible assessment of the intervention programs regarding the physical therapy of patients with mandibular condyle fractures, performed by international experts experienced in the field of maxillofacial surgery, dental surgery and physical therapy. ${ }^{15}$

In the patients treated due to a mandibular condyle fracture in 2017, we applied post-surgical rehabilitation in accordance with the Delphi technique. The methods applied by us earlier, which focused on the directed activization of the stomatognathic system muscles, were also similar to the ones that are included in the Delphi technique. A precisely defined time of use, the number of repetitions of particular exercises and the assessment of rehabilitation effects were the features acquired by us from the specialists applying the Delphi technique in 2016. We did not encounter any scientific publication on the results of the rehabilitation of the oral cavity functions with the use of the Delphi technique. The difficulties recognized in rehabilitation are presented in this article.

\section{Objectives}

The main objective of the present study was to implement the Delphi technique in the mastication organ rehabilitation in patients after the surgical treatment of mandibular condyle fractures, and recording the conditions and results of the rehabilitation.

\section{Material and methods}

The research was approved by the Bioethics Committee of the Pomeranian Medical University in Szczecin, Poland (approval No. KB-0012/30/13). All of the patients included in the study gave written consent for their diagnostic examination results, the obtained surgical treatment and rehabilitation goals to be published.

The research featured 46 of patients aged 17-49 years (the mean age: 29.2 years) treated surgically between January 2, 2017 and December 30, 2017 due to a mandibular condyle fracture. Diagnosis was made on the basis of a clinical examination, a pantomographic X-ray image and a computed tomography (CT) scan of the facial part of the skull. Open reduction and rigid internal fixation was applied, and in some cases, CRMMF was used within a period of 2 weeks. Table 1 presents all information on the treatment and rehabilitation of the patients treated due to a mandibular condyle fracture.

Rehabilitation with the use of Delphi technique was implemented in every patient who had given conscious consent for the complementation of the applied surgical treatment with the directed activization of the stomatognathic system muscles. Rehabilitation was commenced on the $2^{\text {nd }}$ day post-surgically during the patient's stay at the ward under the surgeon's care. Patients in whom there was a necessity of the application of CRMMF, after the fixation removal in the ambulatory conditions, 
Table 1. Fractures of the condylar process treated between January 2, 2017 and December 30, 2017

\begin{tabular}{|c|c|c|c|c|}
\hline \multirow{2}{*}{ Condylar process fracture } & \multirow{2}{*}{$\begin{array}{c}\text { Number } \\
\text { of fractures } \\
n\end{array}$} & \multicolumn{2}{|c|}{ Treatment } & \multirow{2}{*}{$\begin{array}{l}\text { Duration of rehabilitation } \\
\text { [weeks] } \\
\text { (Delphi technique 2016) }\end{array}$} \\
\hline & & ORIF & CRMMF & \\
\hline $\begin{array}{l}\text { Isolated fracture } \\
\text { unilateral } \\
\text { bilateral }\end{array}$ & $\begin{array}{l}14 \\
6\end{array}$ & $\begin{array}{c}13 \\
4\end{array}$ & $\begin{array}{l}1 \\
2\end{array}$ & $\begin{array}{c}3-6 \\
6\end{array}$ \\
\hline Coexisting with mandibular fractures on the same side & 2 & 2 & - & $3-6$ \\
\hline Coexisting with mandibular fractures on the opposite side & 19 & 18 & 2 & 6 \\
\hline Coexisting with bilateral mandibular fractures & 8 & 8 & 2 & $>6$ and $<52$ \\
\hline $\begin{array}{l}\text { Coexisting with bone fractures of the facial part } \\
\text { of the cranium }\end{array}$ & 3 & $\begin{array}{c}2 \\
\text { defragmented he }\end{array}$ & moved - 1 patient & $>6$ and $<52$ \\
\hline Total & 52 & 47 & 8 & $3-52$ \\
\hline
\end{tabular}

ORIF - open reduction and rigid internal fixation; CRMMF - closed reduction and maxillomandibular fixation.

were given detailed information on the self-performance of the exercises designed to restore the TMJ functions. Suggestions concerning food consistency and the size of a mouthful were given to the patients on discharge from hospital or after intermaxillary fixation. Table 2 presents exercises with the suggestions concerning their duration and the number of repetitions, proposed within the Delphi technique.

The assessment of the mastication organ functions was performed at 3, 6 and 52 weeks since the beginning of rehabilitation. The interincisal distance was measured in each patient; in chosen cases, the range and trajectory of the condyle movements, and the trajectory of the secant point during jaw opening were defined with the use of the Zebris ${ }^{\circledR}$ JMA device (Drive Medical, Isny im Allgäu, Germany).

\section{Results}

Among 148 of patients treated surgically due to a mandible fracture in 2017, 46 patients (31\%) were treated due to 52 mandibular condyle fractures. In the case of 47 of the fractures of the mandibular condyles, ORIF was applied. In all of the 47 cases, the reposition and stabilization of bone fragments was achieved. Maxillomandibular fixation was applied in 8 of the patients as complementary treatment for ORIF in bilateral fractures, where dental occlusion was different from the assumed.

Table 2. Exercises and dosages according to the Delphi questionnaire

\begin{tabular}{|l|c|c|}
\multicolumn{1}{|c|}{ Exercise } & $\begin{array}{c}\text { Repetitions } \\
\text { at one time }\end{array}$ & $\begin{array}{c}\text { Repetitions } \\
\text { per day }\end{array}$ \\
\hline $\begin{array}{l}\text { Isometric jaw contractions } \\
\text { (held for } 5 \mathrm{~s} \text { ) }\end{array}$ & $\begin{array}{c}5 \text { contractions } \\
\text { per muscle }\end{array}$ & 3 \\
Jaw opening & 5 movements & 3 \\
Lateral jaw movement & 5 movements & 3 \\
Jaw protrusion & 5 movements & 3 \\
Stretch (held for $5 \mathrm{~s}$ ) & 5 movements & 3 \\
\hline
\end{tabular}

After 6 weeks of rehabilitation, 41 of the 46 patients (89.1\%) assessed the range of their movements within the area of TMJ as satisfying; the interincisal distance was at least $34 \mathrm{~mm}$. Regardless of whether the patients were used to self-control (active jaw opening performed by the patients in front of the mirror to control the range and proper trajectory of movements) for a long time or not, they still assessed the width of jaw opening and its symmetry. Such self-control was also an exercise. At 52 weeks, the patients achieved an opening of at least $42 \mathrm{~mm}$.

The disturbed functions of TMJ recorded after 6 weeks of rehabilitation - lateral deviation in mouth opening, malocclusion or mouth opening $<34 \mathrm{~mm}$ - occurred in less than $1 / 4$ of the patients. Table 3 presents the information on the disturbances of the TMJ functions after surgical treatment and after 6 weeks of rehabilitation due to a mandibular condyle fracture.

Mandibular deviation during opening was present in 9 of the patients and it was in the range of $8-11 \mathrm{~mm}$. Jaw opening in 4 out of 9 of the patients was sufficient. In all of the 9 patients, exercises for jaw opening in front of the mirror, including gentle hand pressure, which works against mandibular deviation from the midline during jaw opening, were suggested.

Occlusion disturbances were recorded in 8 of the patients. Mandibular deviation from the midline in these patients was $1-2 \mathrm{~mm}$. Jaw opening in 3 out of 8 of the patients was sufficient. The revision of the occlusion performed in the 3 patients improved the conditions

Table 3. Disturbed functions of the temporomandibular joint (TMJ) in 46 patients after a condylar process fracture, open reduction and rigid internal fixation (ORIF) and 6 weeks of rehabilitation

\begin{tabular}{|l|c|}
\hline \multicolumn{1}{|c}{ Disturbances in the TMJ functions } & $\begin{array}{c}\text { Number of patients } \\
n\end{array}$ \\
\hline Lateral deviation in mouth opening & 9 \\
Malocclusion & 8 \\
Mouth opening $<34 \mathrm{~mm}$ & 5 \\
Pain in TMJ & 5 \\
\hline
\end{tabular}


in the stomatognathic system. The results were assessed by the patients as positive. In the remaining 5 patients, muscle exercises in front of the mirror were continued. After 52 weeks of rehabilitation, mandibular deviation was present in 2 of the patients and it amounted to $1 \mathrm{~mm}$. The patients accepted the situation and they did not report any problems at rest nor during mastication.

In 5 of the patients, the interincisal distance was of 27-30 mm. These patients complained about painful jaw opening limitation. Spontaneously implemented by these patients analgetic treatment was applied once a day in the morning, when the pain was the greatest. In these patients, the X-ray imaging results were revised and new CT scans were performed in three-dimensional (3D) reconstruction (Table 4). The rehabilitation technique applied earlier was maintained. After 52 weeks of rehabilitation, a jaw opening of 34-44 mm was recorded in these patients (Fig. 1).

Table 4. X-ray images of the fractured condylar processes in the patients in whom the necessary rehabilitation lasted more than 6 weeks

\begin{tabular}{|c|c|c|c|}
\hline Patient & $\begin{array}{l}\text { Chosen X-ray } \\
\text { image of the } \\
\text { condylar process }\end{array}$ & $\begin{array}{l}\text { Fracture } \\
\text { description }\end{array}$ & $\begin{array}{l}\text { Damage } \\
\text { to the ligaments } \\
\text { or muscles }\end{array}$ \\
\hline QX1 & & $\begin{array}{c}\text { multi-fragmented } \\
\text { fracture of the } \\
\text { mandible, fracture } \\
\text { of both condylar } \\
\text { processes, fracture } \\
\text { of both pterygoid } \\
\text { processes, rotation } \\
\text { of the left pterygoid } \\
\text { process }\end{array}$ & $\begin{array}{l}\text { avulsion of the } \\
\text { temporomandibular } \\
\text { ligament, damaged } \\
\text { attachment of the } \\
\text { left temporal muscle }\end{array}$ \\
\hline$Z Y$ & & $\begin{array}{l}\text { dislocation in TMJ, } \\
\text { multi-fragmented } \\
\text { fracture of the } \\
\text { condylar process, } \\
\text { displacement of the } \\
\text { fragments mid-linear } \\
\text { and forward }\end{array}$ & $\begin{array}{l}\text { avulsion of the } \\
\text { temporomandibular } \\
\text { ligament and the } \\
\text { retrodiscal ligament }\end{array}$ \\
\hline$X Y$ & & $\begin{array}{l}\text { multi-fragmented } \\
\text { fracture of the } \\
\text { mandible, recurring } \\
\text { dislocations in TMJ }\end{array}$ & $\begin{array}{l}\text { avulsion of the } \\
\text { upper part of the } \\
\text { lateral pterygoid } \\
\text { muscle with } \\
\text { a fragment of the } \\
\text { condylar head and } \\
\text { the lateral plate } \\
\text { of the pterygoid } \\
\text { process of the } \\
\text { sphenoid bone, } \\
\text { avulsion of the } \\
\text { lateral ligament }\end{array}$ \\
\hline$V X$ & & $\begin{array}{l}\text { vertical fracture } \\
\text { of the mandible } \\
\text { branch, dislocation } \\
\text { in TMJ }\end{array}$ & $\begin{array}{l}\text { avulsion of the } \\
\text { sphenoidmandibular } \\
\text { ligament }\end{array}$ \\
\hline QV & & $\begin{array}{l}\text { multi-fragmented } \\
\text { fracture of the } \\
\text { mandible, fracture } \\
\text { of the condylar } \\
\text { process, dislocation } \\
\text { in TMJ }\end{array}$ & $\begin{array}{l}\text { avulsion of the } \\
\text { temporomandibular } \\
\text { ligament }\end{array}$ \\
\hline
\end{tabular}

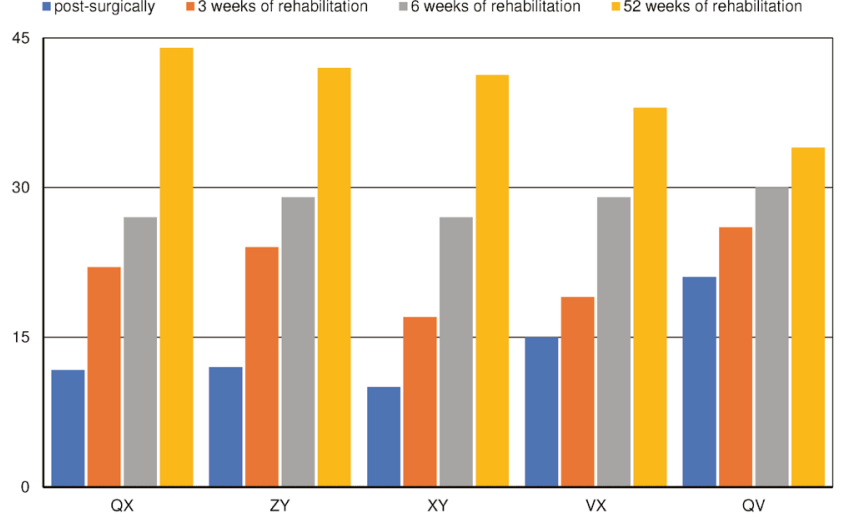

Fig. 1. Interincisal distance in 5 of the patients in whom rehabilitation was prolonged

In patient $\mathrm{XY}$, jaw opening improvement was taking place at the slowest rate. After 6 weeks of rehabilitation, 13 weeks post injury, jaw opening in the patient expanded from 10 to $27 \mathrm{~mm}$. The late beginning of rehabilitation was associated with dislocation in TMJ, which primarily occurred due to a complex injury - a multi-fragmented fracture within the mental region, a bilateral fracture within the area of the mandible angles, a right-side fracture of the condyle process and the styloid process, with the knock-out of lower central incisors (Fig. 2). The displacement of TMJ occurred for the $2^{\text {nd }}$ and $3^{\text {rd }}$ time in the patient, in whom the fragments of the mandible were stabilized through the use of ORIF, and finally permanent maxillomandibular fixation was applied after placing a partial mobile prosthesis in the oral cavity, which recreated lower central incisors. Anxiety about the renewal of the TMJ displacement probably retarded full commitment to rehabilitation.

The changes in the range and shape of the trajectory of the movement of the condyle process during opening/ closing the mouth recorded in patient XY during the $2^{\text {nd }}$ half-year of rehabilitation are shown in Fig. 3 and Fig. 4.

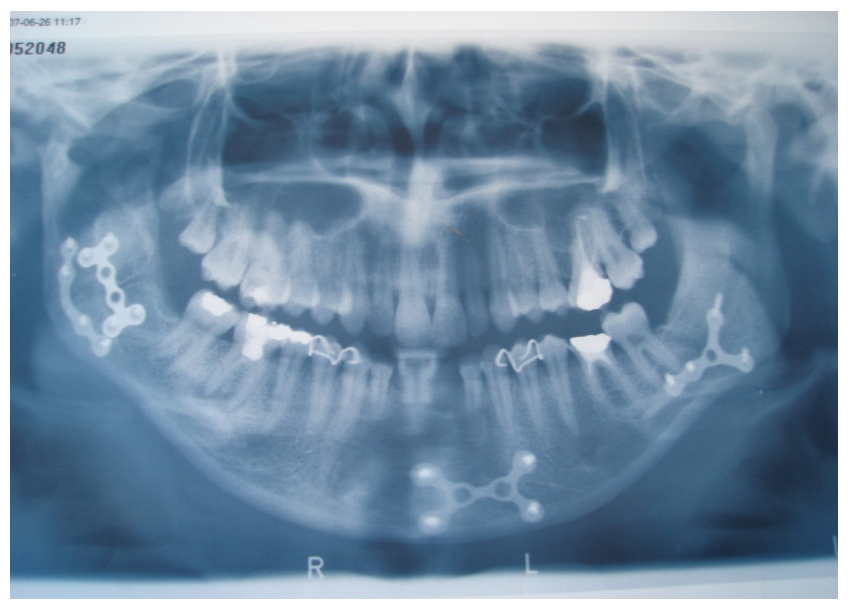

Fig. 2. Pantomogram of female patient $X Y$ - a multi-fragmented fracture of the mandible within the mental region, within both angles, a fracture of the right condylar process as well as the knock-out of lower central incisors 

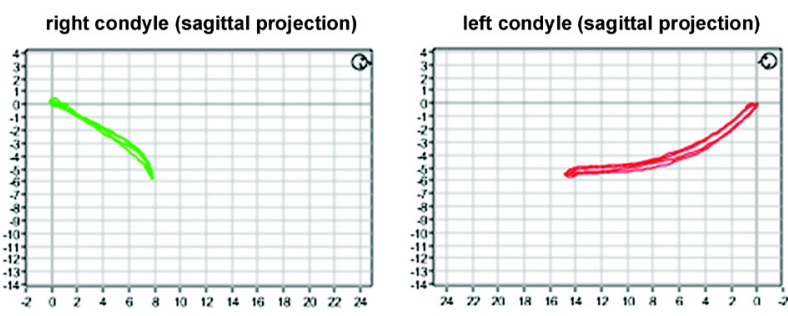

Fig. 3. Range and shape of the condylar track during the opening/closing of the right TMJ and the left TMJ after 26 weeks of rehabilitation
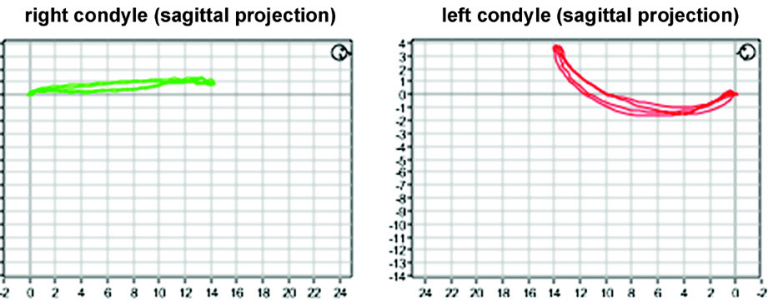

Fig. 4. Range and shape of the condylar track during the opening/closing of the right TMJ and the left TMJ after 52 weeks of rehabilitation

The record made after 26 weeks of rehabilitation showed the shortening and flattening of the trajectory of the fractured and displaced right condyle process as compared to the left side. Another record, after 52 weeks of rehabilitation, showed a longer and flatter trajectory of the right condyle process than in the previous examination.

The change in the trajectory of the incisal point during mouth opening which occurred during the $2^{\text {nd }}$ half-year of rehabilitation is shown in Fig. 5. The record made after 26 weeks of rehabilitation showed a mandible deviation of $5 \mathrm{~mm}$ toward the fractured and displaced condyle throughout the whole movement of opening, especially during its $2^{\text {nd }}$ phase. Another record, made after 52 weeks of rehabilitation, showed a symmetrical trajectory of conducting the mandible with a 3-millimeter deviation toward the contralateral side to the fractured and displaced condyle at the end of the $2^{\text {nd }}$ phase of the opening movement.

The CT scan of the skull in 3D reconstruction performed after 52 weeks of rehabilitation showed the deformation
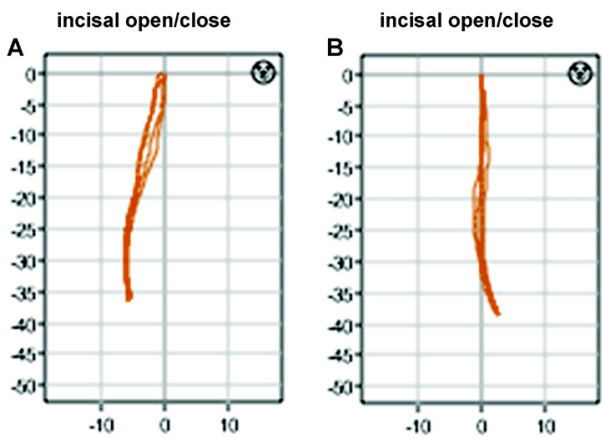

Fig. 5. Trajectory of the incisal point during jaw opening/closing in female patient $X Y$

A - after 26 weeks of rehabilitation; B - after 52 weeks of rehabilitation. of the right condylar process and the cup on the side (Fig. 6). Changes in the shape of the condyle head arose during a year's rehabilitation of the oral cavity functions. At that time, the head of the condyle grew together with the torn off fragment of the head of condyle; the broken off side plate of the pterygoid process was still visible as a free fragment.

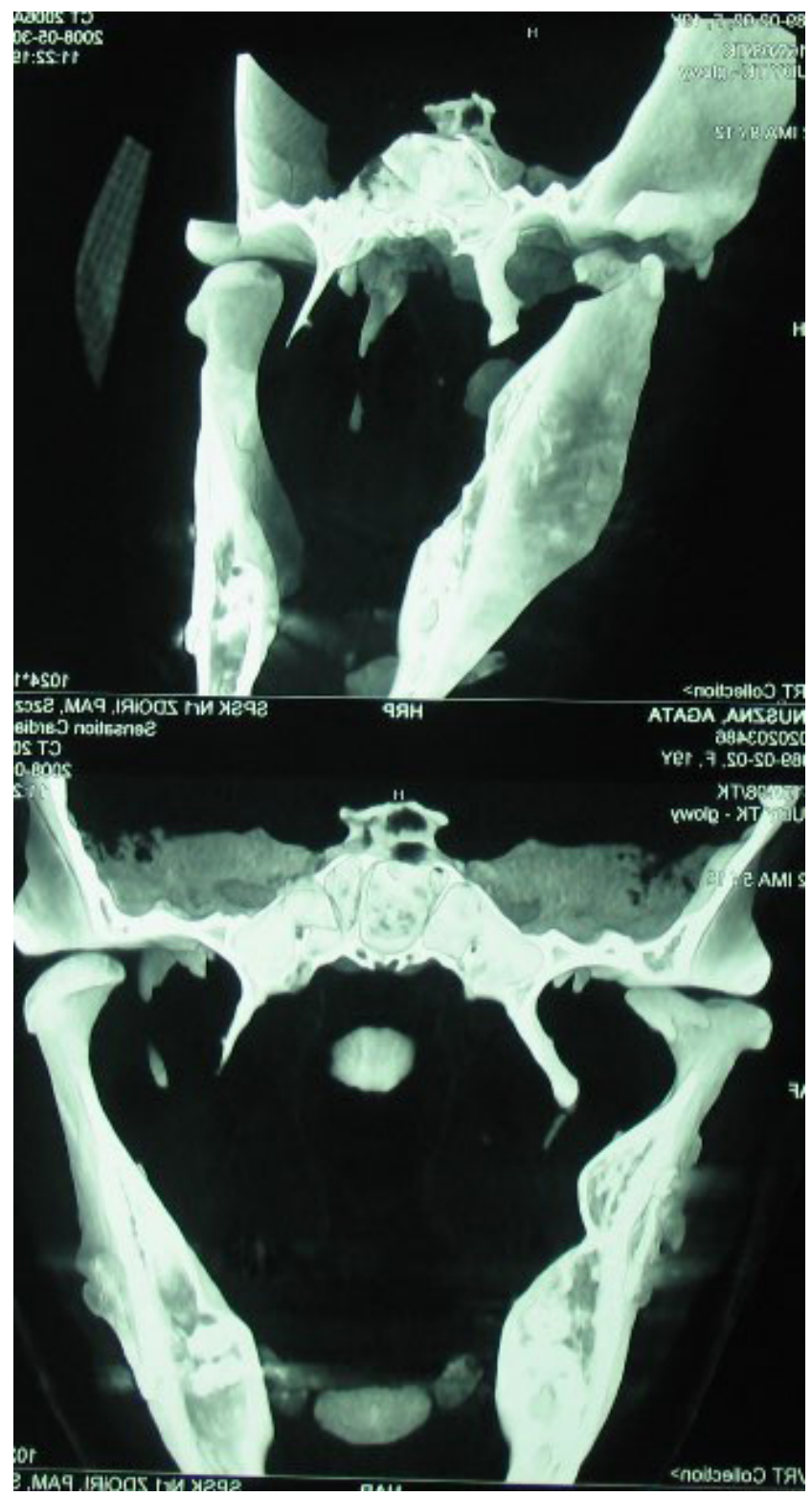

Fig. 6. Computed tomography (CT) scan in three-dimensional (3D) reconstruction of female patient $X Y$ after 52 weeks of rehabilitation 59 weeks after the injury

\section{Discussion}

The Delphi technique was approved as a procedure of rehabilitation in our facility on the basis of the fact that the directed activization of the stomatognathic system muscles - similar to the Delphi technique - had been used for the purpose of rehabilitation after a condyle process fracture for many years. 
Independently of the treatment method applied (ORIF or CRMMF), post-surgical autocorrection and selfcontrol was suggested to each patient. A check-up examination (no complications) was performed a week after ORIF or after the removal of intermaxillary fixation. Another examination, after 3 weeks of rehabilitation, was the $1^{\text {st }}$ assessment of the restoration of the oral cavity functions; it was also the moment when the decision on further rehabilitation was made.

According to the data gathered by van der Merwe and Barnes, the disturbances of the stomatognathic system functions after ORIF performed due to condyle process fractures affect $0-49 \%$ of patients, and after the closed treatment $-11-49 \%$ of patients. ${ }^{14}$ It may be assumed that more than $50 \%$ of patients after the treatment of a mandibular condyle process fracture need the rehabilitation of the oral cavity functions. Self-management is the basic intervention which ensures a simple reversible therapy. However, there is no unambiguous, simple definition of self-management in the literature. There is a dominant opinion that all of the self-management programs have similar general goals, and that the goals may be supplemented with further goals and supporting modules, specifically designed for the needs reported by patients, i.e., focused mainly on the improvement of mouth opening. ${ }^{15}$

Mouth opening lesser than expected by the patient is the main problem after a condylar process fracture. However, there are some jaw opening widths referred to as a norm; according to Agraval et al., it is $50 \mathrm{~mm},{ }^{16}$ and according to Cox and Walker, the minimum is $34 \mathrm{~mm} .{ }^{17}$ A patient's sensation that they can effortlessly or painlessly, and accordingly to their assumptions, open and close their mouth is the most important. The cause of mouth opening limitation may be directly associated with the injury effect. The limitation may also results in the necessity of applying intermaxillary fixation for some time. Determining the cause seems to be important for effective rehabilitation. Pre-surgical orthopantomograms and sagittal CT scans in the described group of patients seem to be insufficient for the assessment of the post-injury changes concerning the bony and soft elements of TMJ. Condylar process fractures are perceived by the authors specialized in the field as difficult for imagining due to the overlapping of many anatomical structures on the condylar process. An oral pantomogram, posteroanterior X-ray images of the mandible, and alternatively a lateral oblique view, are reliable imagining examinations implemented in the diagnosis of fractured craniofacial bones; $\mathrm{CT}$, and especially $\mathrm{CT}$ in $3 \mathrm{D}$ reconstruction, are the methods of choice in the diagnosis of condylar process fractures. ${ }^{3,18}$ According to Mueller et al., spiral CT gives a 100\% chance of defining a mandible fracture, while panoramic tomography gives an $86 \%$ chance. $^{19}$

The symmetry of jaw opening and closing, or more precisely - a lack of the symmetry, is another problem for the patients rehabilitated after a mandibular condyle process fracture. Performing the suggested exercises by patients in front of a mirror results in the multiple repetitions of the desirable symmetrical jaw opening and closing. The majority of the 46 patients treated by us (over $80 \%$ ) presented with the stabilized central closure and symmetrical opening of the jaws after 6 weeks of rehabilitation; in 3 of the patients, a closure correction was performed due to a mandible deviation from the midline of $1-2 \mathrm{~mm}$ in closure. These patients performed the movement of opening symmetrically. In $19 \%$ of the patients presented in Table 3 , there was a significant asymmetry (3-11 $\mathrm{mm})$ during the movement of jaw opening and a slight asymmetry $(1-2 \mathrm{~mm})$ in closure. These patients were encouraged to further rehabilitation.

A similar frequency of mandible deviation during mouth opening and a 3 times lower frequency of inappropriate closure at 6 weeks after ORIF due to a mandibular condyle process fracture are reported by Cuéllar et al. ${ }^{20}$ The authors, based on 6 randomized trials involving 288 patients, suggest a lower probability of malocclusion, lateral deviation in mouth opening and pain in TMJ after surgical management than after conservative management. According to Villarreal et al., the improvement of the stomatognathic system functions achieved by means of ORIF was greater than in the case of CRMMF; however, open treatment increased the frequency of the post-surgical malformations of the condyles and mandible asymmetry. ${ }^{21}$ There is a need for standardizing the methods of assessment of the functions of the stomatognathic system in order to enable a reliable comparison of treatment results. ${ }^{22}$

However, the self-assessment of the TMJ functions performed by the patient is the basis of TMJ rehabilitation accordingly to the Delphi technique. The use of electronic recording systems supported by computers (Zebris ${ }^{\circledR}$ JMA) and modern radiology techniques allows for the assessment of the efficiency of the therapy, especially when rehabilitation does not provide desirable effects within the provided time. According to Kijak et al., recording changes in the TMJ functions over time is beneficial for understanding the occurring improvement and motivating for further exercises. ${ }^{23}$

Tooth loss as a result of an injury, especially the loss of lower incisors after a mandible fracture within the mental region, may cause the loss of space in the dental arch. In a study dealing with the issue, a greater frequency of space loss was shown in patients who - apart from multiple mandible fractures - also had fractures of the condylar processes. ${ }^{24}$ According to the authors, maintaining the space prevents the complications associated with its reduction. Difficulties in prosthetic treatment after CRMMF due to mandibular condyles fractures are associated with restricted jaw opening and an increased tension of the muscles of the stomatognathic system, and the prognosis for a full recovery of its functions is uncertain. ${ }^{25}$ It is then favorable to perform a prosthesis 
as soon as possible to decrease the possibility of the expected difficulties. It is especially important for maintaining a correct occlusive support. It was demonstrated on the basis of the axiographic examinations of patients in whom the medical problem was partial anodontia, the pathological attrition of other teeth and the TMJ dysfunctions. ${ }^{26}$

In our female patient XY, lower central incisors knocked out during a car accident could not be replanted because they were lost in the damaged car. A partial movable prosthesis made 5 weeks after the injury maintained the space in the dental arch in place of the knocked out incisors and participated in dental occlusion until permanent intermaxillary fixation was put.

The late exposure (CT with $3 \mathrm{D}$ reconstruction was performed 5 weeks after the injury) of the avulsion of the lateral pterygoid muscle with a fragment of the head of the condylar process and the lateral plate of the pterygoid process was not only a diagnostic issue for us. Questions regarding further treatment have only partially been answered in experimental research. ${ }^{27,28}$ Both of the above-mentioned studies showed the lateral pterygoid muscle as an element which stimulates distractive osteogenesis after a condylar process fracture, and which along with the injured joint disk may be an important factor in the etiology of TMJ ankylosis. ${ }^{27,28}$ In case of disruption of the muscle, the stimulation of osteogenesis will not take place.

In the case of our female patient XY, the late diagnosis of the avulsion of the lateral pterygoid muscle was the cause of the recurring dislocation of the condylar process. It was probable that the muscle avulsion and functional rehabilitation prevented TMJ from getting stiff.

\section{Conclusions}

Autocorrection and self-control were the right methods to improve the TMJ functions after the surgical treatment of condylar process fractures. The external control exercised by a maxillofacial surgeon enabled the assessment of rehabilitation efficiency as well as signalized the need for finding circumstances that inhibit the restoration of the TMJ functions. Further assessment of the radiological documentation, supplemented with $\mathrm{CT}$ with 3D reconstruction validated previous assumptions that the condylar process fracture was accompanied by serious injuries of muscles and joint ligaments. Our observations point to the fact that rehabilitation after surgical treatment of a condylar process fracture may be long-lasting and it should be started as soon as possible.

\section{ORCID iDs}

Anna Rzewuska (1) https://orcid.org/0000-0002-2569-0787

Edward Kijak (1) https://orcid.org/0000-0003-4110-5987

Ludmiła Halczy-Kowalik (1) https://orcid.org/0000-0001-6784-3692

\section{References}

1. Silvennoinen U, lizuka T, Lindqvist C, Oikarinen K. Different patterns of condylar fractures: An analysis of 382 patients in a 3-year period. J Oral Maxillofac Surg. 1992;50(10):1032-1037. doi:10.1016/0278-2391(92)90484-h

2. Miloro M. Considerations in subcondylar fracture management. Arch Otolaryngol Head Neck Surg. 2004;130(10):1231-1232. doi:10.1001/archotol.130.10.1231

3. Naeem A, Gemal H, Reed D. Imaging in traumatic mandibular fractures. Quant Imaging Med Surg. 2017;7(4):469-479. doi:10.21037/qims.2017.08.06

4. Mitchell DA. A multicentre audit of unilateral fractures of the mandibular condyle. Br J Oral Maxillofac Surg. 1997;35(4):230-236. doi:10.1016/s0266-4356(97)90038-3

5. Choi KY, Yang JD, Chung HY, Cho BC. Current concepts in the mandibular condyle fracture management part I: Overview of condylar fracture. Arch Plast Surg. 2012;39(4):291-300. doi:10.5999/aps.2012.39.4.291

6. Eckelt U, Schneider M, Erasmus F, et al. Open versus closed treatment of fractures of the mandibular condylar process - a prospective randomized multi-centre study. J Craniomaxillofac Surg. 2006;34(5):306-314. doi:10.1016/j.jcms.2006.03.003

7. Haug RH, Assael LA. Outcomes of open versus closed treatment of mandibular subcondylar fractures. J Oral Maxillofac Surg. 2001;59(4):370-375, discussion 375-376. doi:10.1053/joms.2001.21868

8. Blumer M, Guggenbübl T, Wagner MEH, Rostetter C, Rücker M, Gander T. Outcome of surgically treated fractures of the condylar process by an endoscopic assisted transoral approach. J Oral Maxillofac Surg. 2019;77:133.e1-133.e9. doi:10.1016/j.joms.2018.08.013

9. Anehosur V, Joshi A, Rajendiran S. Endoscopic-assisted intraoral open reduction internal fixation of mandibular subcondylar fractures: Initial experiences from a tertiary-care maxillofacial centre in India. Craniomaxillofac Trauma Reconstr. 2018;11(3):183-191. doi:10.1055/s-0037-1603457

10. Van der Merwe A, Barnes R. The need for physiotherapy intervention for mandibular condyle fracture patients: A needs analysis. S Afr Dent J. 2015;70(5):196-199.

11. Krzemień J, Bańczyk $Ł$, Baron S, Niedzielska I. The influence of the condylar fracture treatment method on mandible dynamics. Dent Med Probl. 2017;54(4):353-359. doi:10.17219/dmp/80748

12. Pagliotto da Silva A, Sassi FC, Bastos E, Alonso N, Furquim de Andrade CR. Oral motor and electromyographic characterization of adults with facial fractures: A comparison between different fracture severities. Clinics (Sao Paulo). 2017;72(5):276-283. doi:10.6061/clinics/2017(05)04

13. Boyde A. The real response of bone to exercise. J Anat. 2003;203(2):173-189. doi:10.1046/j.1469-7580.2003.00213.x

14. Van der Merwe A, Barnes R. The development of a physiotherapy intervention programme for mandibular condyle fracture patients. S Afr Dent J. 2016;71(5):212-217.

15. Durham J, Al-Baghdadi M, Baad-Hansen L, et al. Self-management programmes in temporomandibular disorders: Results from an international Delphi process. J Oral Rehabil. 2016;43(12):929-936. doi:10.1111/joor.12448

16. Agrawal J, Shenai PK, Chatra L, Kumar PY. Evaluation of normal range of mouth opening using three finger index: South India perspective study. Indian J Dent Res. 2015;26(4):361-365. doi:10.4103/0970-9290.167638

17. Cox SC, Walker DM. Establishing a normal range for mouth opening: Its use in screening for oral submucous fibrosis. Br J Oral Maxillofac Surg. 1997;35(1):40-42. doi:10.1016/s0266-4356(97)90007-3

18. Ceallaigh PO, Ekanaykaee K, Beirne CJ, Patton DW. Diagnosis and management of common maxillofacial injuries in the emergency department. Part 2: Mandibular fractures. Emerg Med J. 2006;23(12):927-928. doi:10.1136/emj.2006.035956

19. Mueller RV, Czerwiński R, Lee C, Kellman RM. Condylar fracture repair: Use of the endoscope to advance traditional treatment philosophy. Facial Plast Surg Clin North Am. 2006;14(1):1-9. doi: 10.1016/j.fsc.2005.10.004

20. Cuéllar J, Santana J, Núñez C, Villanueva J. Surgical or conservative treatment for mandibular condyle fractures. Medwave. 2018;18(7):e7344. doi:10.5867/medwave.2018.07.7351 
21. Villarreal PM, Monje F, Junquera LM, Mateo J, Morillo $A J$, González C. Mandibular condyle fractures: Determinants of treatment and outcome. J Oral Maxillofac Surg. 2004;62(2):155-163. doi:10.1016/j.joms.2003.08.010

22. Nussbaum ML, Laskin DM, Best AM. Closed versus open reduction of mandibular condylar fractures in adults: A meta-analysis. J Oral Maxillofac Surg. 2008;66(6):1087-1092. doi:10.1016/j.joms.2008.01.025

23. Kijak E, Frączak BA, Rucińska-Grygiel B. The effect of orthodontic treatment on the quality of mandibular movement tracks in T-scan and Zebris JMA instrumental studies [in Polish]. Dent Forum. 2016;44(1):45-52. doi:10.20883/df.2016.7

24. Rahpeyma A, Khajehahmadi S, Abdollahpour S. Mandibular symphyseal/parasymphyseal fracture with incisor tooth loss: Preventing lower arch constriction. Craniomaxillofac Trauma Reconstr. 2016;9(1):15-19. doi: 10.1055/s-0035-1551542

25. Wieczorek A, Loster JE. Possibility of prosthetic rehabilitation after no surgical treatment fractures of mandible condyle [in Polish]. Implantoprotetyka. 2009;10(4):37-40.

26. Krzemień J, Baron S. Axiographic and clinical assessment of temporomandibular joint function in patients with partial edentulism. Acta Bioeng Biomech. 2013;15(1):19-26.

27. Liu CK, Liu P, Meng FW, et al. The role of the lateral pterygoid muscle in the sagittal fracture of mandibular condyle (SFMC) healing process. Br J Oral Maxillofac Surg. 2012;50(4):356-360. doi:10.1016/j.bjoms.2011.05.015

28. Deng TG, Liu CK, Liu P, et al. Influence of the lateral pterygoid muscle on traumatic temporomandibular joint bony ankylosis. BMC Oral Health. 2016;16(1):62. doi:10.1186/s12903-016-0220-1 